\title{
UPAYA MENINGKATKAN PERAN MGMP MATEMATIKA SMK KABUPATEN MALANG MELALUI PELATIHAN PEMBUATAN E-MODUL MATEMATIKA SMK
}

\author{
EFFORT TO IMPROVE THE RULE VOCATIONAL SCHOOL MATHEMATICS \\ TEACHER'S FORUM IN MALANG REGENCY THROUGH THE TRAININGOF E- \\ MODUL MATHEMATICS TEACHERS' FORUM
}

\author{
${ }^{1)}$ Nyamik Rahayu Sesanti, ${ }^{2)}$ Retno Marsitin, ${ }^{3)}$ Rini Agustina \\ ${ }^{1)}$ Prodi Pendidikan Guru Sekolah Dasar, ${ }^{2}$ Prodi Pendidikan Matematika, ${ }^{3)}$ Prodi Sistem Informasi \\ ${ }^{1)}$ nyamik@unikama.ac.id, ${ }^{2)}$ mars_retno@unikama.ac.id, ${ }^{3)}$ ryfany@gmail.com \\ Universitas Kanjuruhan Malang \\ Jl. S. Supriadi No.48 Malang JawaTimur
}

\begin{abstract}
ABSTRAK
Kegiatan pengabdian Masyarakat ini ditujukan untuk Musyawarah Guru Mata Pelajaran (MGMP) Matematika SMK, yang merupakan forum profesionalisme untuk meningkatkan kompetensi dan kinerja guru matematika SMK. Tujuan kegiatan pengabdian masyarakat ini adalah; (1) meningkatkan peran dan fungsi MGMP Matematika SMK kabupaten Malang dalam memperbaiki kompetensi dan kinerja guru matematika SMK, (2) meningkatkan pemahaman guru matematika SMK terhadap langkahlangkah pembuatan e-modul dan (3) meningkatkan ketrampilan pembuatan e-modul matematika SMK bagi guru matematika SMK Kabupaten Malang. Metode yang digunakan dalam kegiatan ini adalah; (1) pendampingan kepada pengurus MGMP untuk mengkaji ulang program kerja yang sudah ditentukan, (2) mengadakan workshop pembuatan modul matematika SMK, (3) pelatihan dan pendampingan secara berkelompok kepada guru matematika SMK pada proses kepenulisan modul matematika SMK, (4) Workshop pembuatan e-modul matematika SMK, dan (5) desiminasi e-modul matematika SMK oleh guru matematika SMK Kabupaten. Hasil yang dicapai adalah peningkatan kualitas pertemuan MGMP Matematika SMK Kabupaten Malang dan peningkatan ketrampilan pembuatan e-modul Matematika SMK bagi gurunya. Produk yang dihasilkan dari kegiatan ini adalah e-modul matematika SMK.
\end{abstract}

\section{Kata Kunci : MGMP Matematika SMK, Guru Matematika SMK, Pembuatan e-modul matematika}

\section{ABSTRACT}

The community service program was conducted to the Vocational School Mathematics Teachers' Forum (MGMP), a professionalism forum for elevating the competence and performance of the vocational school teachers teaching Mathematics. The program was aimed at: (1) improving the roles and functions of the Vocational School Mathematics Teachers' Forum in Malang Regency, (2) enhancing vocational school Mathematics teachers' understanding of the procedures of creating Mathematics emodules, and (3) upgrading the vocational school Mathematicsteachers' skills in creating their Mathematics e-modules. The methods applied were: (1) mentoring the committees of the teachers' forum in reviewing their work plans, (2) conducting a writing vocational school Mathematics module workshop, (3) training and mentoring the vocational school Mathematics teachers in writing their Mathematics modules in groups, (4) conducting a workshop of creating vocational school Mathematics e-modules, and (5) disseminating the Mathematics e-modules by vocational school Mathematics teachers in Malang Regency. The results of the program were the quality improvement of Mathematics teachers' forum's meetings and the writing Mathematics e-module skills' improvement of the Mathematics teachers in Malang Regency. The products of this community service program were Mathematics e-modules for vocational school students.

Keywords: Vocational School Mathematics Teacher's Forum, Vocational School Mathematics Teachers, vocational school Mathematics e-module writing 


\section{PENDAHULUAN}

MGMP merupakan wadah profesional guru mata pelajaran yang berada pada suatu wilayah kabupaten/ kota/ kecamatan/ sanggar/ gugus sekolah. MGMP berfungsi sebagai sarana komunikasi, belajar, bertukar pikiran dan pengalaman dalam meningkatkan kinerja guru sebagai praktisi perubahan reorientasi pembelajaran di kelas (Anwar, 2011). Ruang lingkup MGMP meliputi guru mata pelajaran pada SMA/SMK negeri dan swasta, baik yang berstatus PNS (Pegawai Negeri Sipil) maupun swasta dan atau guru tidak tetap atau honorarium.Tujuan pembetukan MGMP adalah untuk memperluas wawasan dan pengetahuan guru dalam pembelajaran, meningkatkan ketrampilan guru, meningkatkan profesionalisme guru dan kompetensi guru (Kemendikbud, 2013).

$$
\text { MGMP juga merupakan }
$$

perkumpulan dari guru mata pelajaran untuk memecahkan segala permasalahan dalam proses belajar mengajar di sekolah. Dengan demikian pertemuan yang berkualitas dan mampu memberikan kontribusi kepada guru sangat penting untuk dilaksanakan.Peran forum pertemuan guru di MGMP ini sangat strategis karena digunakan sebagai sarana untuk peningkatan kompetensi guru dan kinerja guru (Mahmud, 2013).

Mitra dari kegiatan ini adalah MGMP Matematika SMK wilayah Kepanjen dan Turen. Guru matematika di SMK tersebut minimal sudah menempuh pendidikan formal pada jenjang S-1 bahkan beberapa sudah lulusan S-2 dan beberapa juga masih ada yang sedang menempuh kuliah S-2. Selain dari tingkat pendidikan diperoleh juga informasi adanya sebagian besar guru Matematika sudah tersertifikasi.

Pembentukan MGMP matematika SMK Kabupaten Malang berdasarkan musyawarah guru mata pelajaran matematika SMK se-Kabupaten Malang dan arahan dari ketua MKKS Kabupaten Malang. Adapun tujuan pembentukannya adalah untuk mewadahi dan menyalurkan aspirasi dan prakarsa guru. Program Kerja Tahunan MGMP Matematika SMK Kabupaten Malang diantaranya adalah;1) program koordinasi terhadap proses kegiatan belajar mengajar dengan sekolah, 2) program koordinasi terhadap pemberdayaan guru mata pelajaran matematika, 3) program pengembangan MGMP Matematika SMK Kabupaten Malang, 4) program kerjasama dengan komponen pendukung pendidikan, 5) program kegiatan intern organisasi, meliputi kerjasama dengan instansi/institusi terkait, sosialisasi dan koordinasi akan kebutuhan materi pelajaran matematika, 6) program kegiatan Pengembangan sumber daya guru matematika sebagai salah satu komponen pendidikan di SMK.

Hanya saja, MGMP Matematika SMK Kabupaten Malang belum optimal mengembangkan kompetensi guru dan mengembangkan metode pembelajaran yang kolaboratif di kelas maupun di luar kelas. MGMP belum dapat membantu guru dalam berbagi ide tentang fakta, rencana, materi dan bahan ajar matematika. Wawasan dan pengetahuan guru matematika SMK untuk mewujudkan pembelajaran yang efektif, efisien dan menyenangkan belum didapatkan dari MGMP. Oleh karenanya peran MGMP dalam meningkatkan mutu pembelajaran perlu ditingkatkan.

Respon MGMP terhadap kemajuan teknologi informasi perlu ditingkatkan. Karena kemajuan teknologi informasi yang demikian pesat dapat dimanfaatkan dalam pembelajaran.MGMP harus mampu memberikan kontribusi guru dalam hal kemajuan teknologi. Begitu juga, guru itu sendiri harus mampu mengintegrasikan teknologi informasi dan komunikasi dalam kegiatan pembelajaran. Hal itu harus terus dilakukan agar kualitas proses dan hasil pembelajaran lebih baik (Husain, 2014). 
Kemampuan

penggunaan

teknologi informasi dan komunikasi sangat bermanfaat bagi guru SMK. Hal ini dikarenakan salah satu system pelatihan kompetensi pada pendidikan kejuruan adalah system magang bagi siswa SMK yang operasionalnya disebut dengan Pendidikan Sistem Ganda (PSG) dan saat ini sering disebut sebagai Praktik Kerja Industri (Prakerin) (Arfandi, 2009). Adanya kurikulum SMK yang mengharuskan Prakerin, mengakibatkan tatap muka pelajaran matematika berkurang, sehingga membutuhkan interaksi pembelajaran matematika yang efektif untuk siswa yang sedang Prakerin. Padahal rata-rata siswa mempunyai fasilitas yang bisa dipergunakan untuk menunjang pembelajaran pada saat Prakerin, misalkan HP Android dan Laptop. Selama ini fasilitas tersebut kurang dimanfaatkan oleh guru SMK Kepanjen dan Turen agar siswa belajar melalui media yang mereka punya, karena kurangnya kemampuan guru SMK dalam penggunaan teknologi informasi dan komunikasi.

Permasalahan yang dihadapi oleh MGMP Matematika SMK Kabupaten malang secara umum adalah:

1. Kualitas koordinasi rutin masih perlu ditingkatkan. Pertemuan MGMP yang dilaksanakan selama ini hanya berkoordinasi untuk pembuatan soalsoal tryout matematika saja. Adapun diskusi aktif mengenai peningkatan kualitas dalam pembelajaran belum pernah dilakukan.

2. Program pengembangan kompetensi guru matematika masih belum berjalan optimal. Hal ini ditandai dengan masih rendahnya kreatifitas guru anggota MGMP dalam membuat bahan ajar berdasarkan karakteristik peserta didik. Sebagaian besar mereka menggunakan buku cetakan yang sudah ada, sehingga sumberdaya Guru yang menjadi anggota MGMP belum semuanya produktif.
3. Diterapkannya kurikulum SMK yang mengharuskanprakerin, berakibat tatap muka pelajaran matematika berkurang. Fungsi MGMP untuk membantu proses pembelajaran belum optimal.

Berdasarkan permasalahan mitra yang dihadapi maka tujuan kegiatan program kemitraan kemasyarakatan ini adalah; (1) meningkatkan peran dan fungsi MGMP Matematika SMK kabupaten Malang dalam memperbaiki kompetensi dan kinerja guru matematika SMK, (2) meningkatkan pemahaman guru matematika SMK terhadap langkahlangkah pembuatan e-modul dan (3) meningkatkan ketrampilan pembuatan emodul matematika SMK bagi guru matematika SMK Kabupaten Malang.

\section{METODE}

Metode yang untuk menyelesaikan masalah mitra adalah pendampingan terhadap pengurus MGMP Matematika SMK Kabupaten Malang dalam menyusun program kerja tahunan. Selanjutnya melaksanakan model kegiatan yang berkualitas dalam meningkatkan profesionalisme guru matematika SMK. Kegiatan tersebut adalah workshop terkait pembuatane-modul pembelajaran matematika SMK. Untuk melatih ketrampilan dalam pembuatan bahan ajar, akan dilaksanakan pelatihan dan pendampingan kelompok guru dalam pembuatan e-modul pembelajaran matematika SMK. Selanjutnya, produk emodul didesiminasikan di forum MGMP Matematika SMK Kabupaten Malang.

Adapun langkah-langkah praktis yang dilaksanakan adalah sebagai berikut :

1. Pendampingan kepada pengurus MGMP untuk mengkaji ulang program kerja yang sudah ditentukan. Pendampingan ini dimaksudkan untuk meningkatkan kualitas kegiatan MGMP. Diharapkan kegiatan MGMP memberikan kontribusi besar terhadap peningkatan profesionalitas guru. 
2. Workshop pembuatan modu lmatematika SMK, dengan tujuan agar guru matematika anggota MGMP memahami tentang langkah-langkah pembuatan bahan ajar berbentuk modul pembelajaran matematika SMK dan mampu membuat bahan ajar berbentuk modul pembelajaran matematika SMK. Dalam workshop ini, disampaikan tentang definisi dan jenis-jenis bahan ajar, bahan ajar yang berdasarkan karakteristik peserta didik dan prinsip-prinsip pembuatan bahan ajar. Kemudian guru juga dibekali dengan pengetahuan tentang bahan ajar yang berupa modul pembelajaran, perbedaan modul pembelajaran dengan bahan ajar yang lain, modul pembelajaran dengan pendekatan teori tertentu dan prinsip-prinsip dalam pembuatan modul pembelajaran. Berikutnya, diadakan diskusi dan tanya jawab antara guru dan pemateri.

3. Pelatihan dan pendampingan kelompok guru dalam pembuatan modul matematika SMK. Tim pengabdian masyarakat mendampingi kelompok guru dalam pembuatan modul. Tim pengabdian masyarakat membentuk kelompok-kelompok guru dan membagi materi matematika SMK yang akan dibuatkan modul. Tim pengabdian masyarakat mendampingi pembuatan alur berfikir modul masingmasing kelompok.Tim pengabdian memberikan kesempatan kepada kelompok guru untuk bertanya dan berdiskusi dalam proses pembuatanya. Target dari pendampingan ini adalah terbentuknya modul dari masingmasing kelompok guru. Kelompok guru juga diberikan kesempatan untuk mempresentasikan modulnya agar mendapatkan masukan, saran dan kritik dari guru lain dan tim pengusul.

4. Workshop pembuatan e-modul pembelajaran matematika SMK. Pada workshop ini disampaikan manfaat dari e-modul pembelajaran matematika
SMK dan langkah-langkah pembuatan e-modul. Kelompok guru mempraktekkan langsung pembuatan e-modul dengan pendampingan pemateri.

5. Desiminasi produk bahan ajar berbentuk e-modul matematika SMK ke guru matematika SMK seKabupaten Malang. Kelompok guru mendesiminasikan e-modul yang sudah dihasilkan. Forum juga diberikan kesempatan untuk bertanya dan memberikan tanggapan.

\section{HASIL DAN PEMBAHASAN}

Ketercapaian program pendampingan kepada pengurus MGMP untuk mengkaji ulang program kerja yang sudah ditentukan adalah perumusan program tahunan MGMP SMK Kabupten Malang. Kehadiran pengurus MGMP dalam kegiatan ini $64 \%$, yaitu dari 14 pengurus MGMP Matematika SMK kabupaten Malang yang hadir ada 9 pengurus.

Kegiatan pendampingan ini bertujuan agar kegiatan MGMP lebih terarah dan optimal dalam meningkatkan kinerja guru matematika SMK. Adanya dokumen program tahunan MGMP akan menjadi acuan dalam kegiatan yang akan dilaksanakan MGMP. Sehingga dokumen program tahunan harus ada dan direvisi setiap tahunnya. Hal ini merupakan faktor pendukung yang harus ada dalamo rganisasi, yaitu adanya buku pedoman atau petunjuk teknis dalam penyelenggaraan organisasi agar jelas uraian dan pembagian tugasnya (Arfandi, 2009).

Kegiatan selanjutnya adalah workshop pembuatan modul matematika SMK. Materi yang disampaikan adalah pentingnya pembuatan modul, definisi modul oleh para ahli. Kemudian pemateri menyampaikan beberapa contoh modul. Trik pembuatan modul juga dijelaskan untuk mempermudah dalam pembuatan 
modul. Pembahasan selanjutnya adalah pendekatan-pendekatan yang bisa digunakan dalam menyusun modul. Sebagai penutup pemateri memotivasi guru untuk kreatif dalam menyusun modul.

Ketercapaian program kegiatan workshop pembuatan modul adalah modul matematika yang dibuat oleh kelompok guru matematika SMK Kabupaten Malang. Target yang didatangkan adalah 60 guru matematika SMK Kabupaten Malang, yang hadir 50 guru atau ketercapaian kehadiran $83,33 \%$.

Untuk meningkatkan ketrampilan pembuatan modul dilaksanakan kegiatan pelatihan dan pendampingan kepada guru matematika SMK. Tim pengabdian masyarakat mendampingi peserta pelatihan dalam pembuatan modul. Tim pengabdian membagi kelompok kerja sesuai sektor MGMP. Hanya saja, pembagian kelompok berdasarkan sektor membuat banyaknya anggota kelompok tidak merata. Proses pengerjaannya juga sulit karena jarang ketemu. Akhirnya banyak yang mengusulkan pembagian kelompok menurut sekolahnya masing-masing. Tim pengabdian masyarakat beserta ketua MGMP menyetujui usulan tersebut.

Materi yang akan didesain dalam modul sesuai Kopetensi Dasar pada Kurikulum 2013 revisi 2016. Ketua MGMP dibantu 2 pengurusnya membagi Kopetensi Dasar pada setiap kelompok. Tim pengabdian mengingatkan bahwa kegiatan siswa yang dirancang pada modul berbeda dengan Lembar Kerja Peserta Didik. Kegiatan siswa pada modul diarahkan pada kemandirian siswa dalam belajar. Apalagi untuk siswa SMK yang sedang prakerin. Peserta antusias dalam membuat modul. Beberapa peserta aktif bertanya pada proses pengerjaanya. Hanya saja, karena terbatasnya literatur dan fasilitas wifi pengerjaan modul agak terhambat. Peserta meminta waktu seminggu lagi untuk menyelesaikan modulnya. Akhirnya disepakati mekanisme monitoring penyelesaian desain modulnya Mekanismenya yaitu melalui grup WA yang dipantau oleh ketua MGMP dan tim pengabdian. Bagi kelompok yang sudah menyelesaikan sebelum seminggu boleh dikumpulkan melalui grup WA.

Ketercapaian program worshop pembuatan e-modul adalah e-modul matematika yang dibuat oleh kelompok guru matematika SMK Kabupaten Malang. Target yang didatangkan adalah 60 guru matematika SMK Kabupaten Malang, yang hadir 50 guru atau ketercapaian kehadiran $83,33 \%$.

Modul yang dibuat oleh peserta kemudian diubah dalam bentuk e-modul. Hal ini dilaksanakan pada kegiatan workshop pembuatan e-modul. Target dari pelaksanaan workshop ini adalah guru matematika SMK dapat membuat e-modul dengan bantuan aplikasi sigil. Materi yang disampaikan adalah langkah-langkah menggunakan aplikasi sigil. Selain menyampaikan materi, pemateri juga membimbing peserta dalam pembuatan emodul nya. Modul yang akan dijadidikan e-modul adalah modulyang sudah dikerjakan sebelumnya. Sehingga pada worshop ini hanya mengubah modul dalam bentuk dokumen ke e-modul yang bisa di buka pada HP Android.

Peserta yang hadir pada workshop ini sebanyak 60 orang. Mereka duduk sesuai dengan kelompoknya masing-masing.Ketercapaian program worshop pembuatan e-modul adalah emodul matematika yang dibuat oleh kelompok guru matematika SMK Kabupaten Malang. Target yang didatangkan adalah 60 guru matematika SMK Kabupaten Malang, yang hadir 50 guru atau ketercapaian kehadiran 83,33\%.

Tim pengabdian dan Pengurus MGMP memlih kegiatan workshop dan pelatihan. Peserta pada kegiatan ini adalah guru bidang studi matematika SMK.Mereka mempunyai keahlian dalam bidang matematika SMK. Dalam kegiatan 
ini terdapat pelatihan pembuatan e-modul. Mereka bekerja untuk membuat e-modul secara berkelompok untuk mendapatkan pengalaman secara praktek langsung.Mereka juga diarahkan oleh ahli pembelajaran dan ahli IT. Hal ini juga dilakukan oleh Zuriah, Sunaryo, \& Yusuf, (2016)

Proses pelaksanaan program pengabdian dalam bentuk workshop dengan orientasi praktik dan workshop dengan mengedepankan prinsip partnership yangamenjadikan proses berlangsung interaktif dan dinamis berkembang secara konstruktif.

Peserta mendesiminasikan hasil kerjanya pada forum desiminasi MGMP Matematika SMK Kabupaten Malang. Peserta yang lain memberikan masukanmasukan dan pertanyaan terhadap hasil karya yang disampaikan.pelaksanaan kegiatan ini dipandu oleh tim pengabdian masyarakat.Ketercapaian program kegiatan desiminasi pembuatan e-modul adalah $83.33 \%$, yaitu 50 guru matematika SMK Kabupaten Malang.

Kegiatan yang telah dilakukan oleh tim pengabdian dan MGMP Matematika SMK Kabupaten Malang, diharapkan mampu memotivasi Guru Matematika SMK untuk kreatif membuat e-modul dengan memanfaatkan teknologi yang sudah tersedia. Guru Matematika SMK juga diharapkan bias mengembangkan pada materi-materi matematika yang lain. Hal ini senada dengan pendapat Husain (2014), yaitu upaya untuk mengoptimalkan pemanfaatan teknologi informasi dan komunikasi dalam pembelajaran adalah memberikan motivasi kepada para guru berkenaan dengan pemanfaatan teknologi informasi dan komunikasi dalam pembelajaran serta berbagai pelatihan dan workshop baik yang diselenggarakan oleh pihak sekolah secara mandiri maupun dari pihak luar sekolah.
Adapun beberapa hasil yang dicapai pada kegiatan ini adalah sebagai berikut:

1. Peningkatan pemahaman dan ketrampilan pembuatan modul matematika SMK. Hal ini ditujukkan dengan kreatifitas para peserta dalam membuat modulnya. Salah satu contoh modul yang dihasilkan:

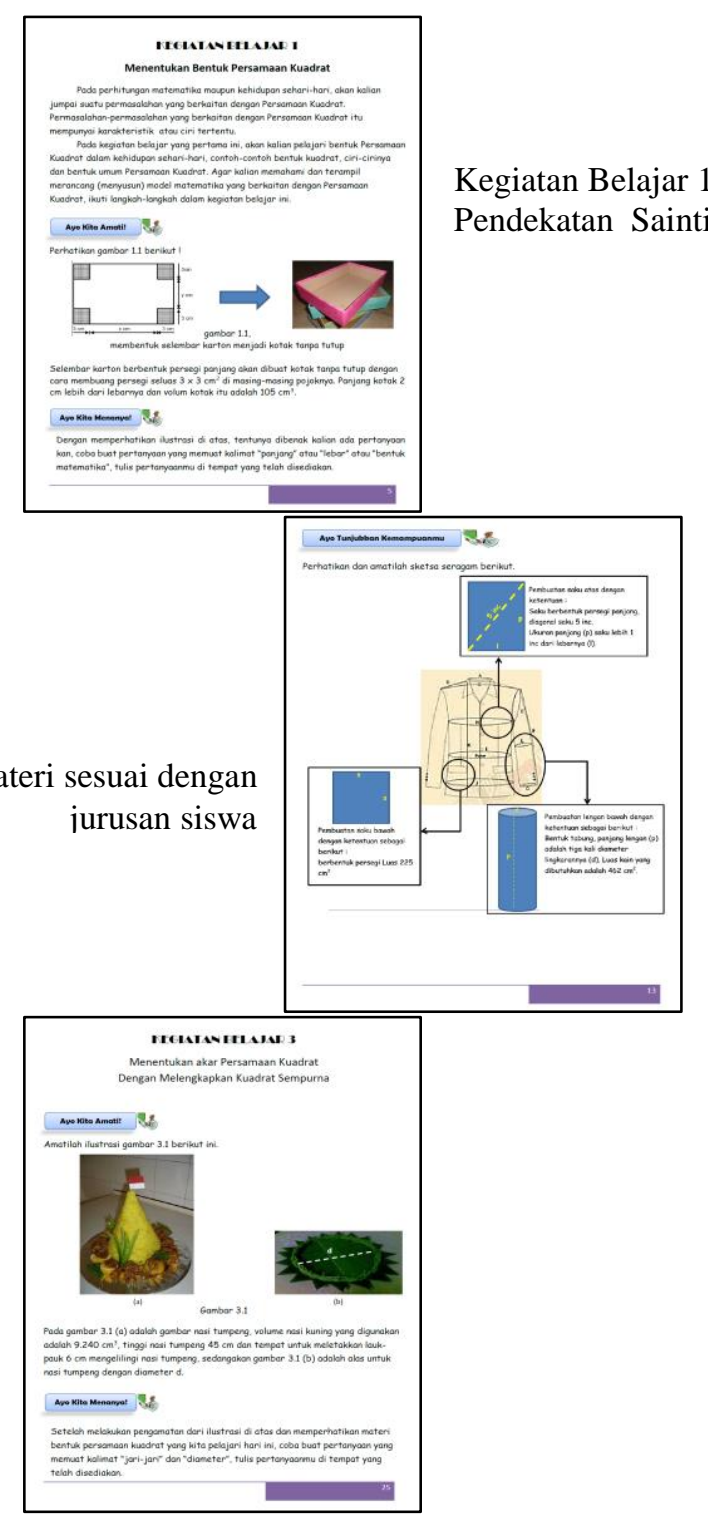

Gambar 1.Contoh modul yang dihasilkan

Gambar 1 menunjukkan modulyang menggunakan pendekatan dalam proses 
pembelajaran dan juga materi sesuai dengan jurusan peserta didik.

Adanya peningkatan dan pemahaman guru SMK dalam pembuatan modul ini diharapkan berpengaruh terhadap peningkatan kompetensi dan kesiapan guru dalam pembelajarannya.Terutama dalam penerapan kurikulum 2013 yang menuntut kreatifitas guru. Kesiapan guru dalam pembelajaran berpengaruh terhadap implementasi kurikulum 2013 (Kusufa, 2013).

2. Peningkatan pemahaman terhadap langkah-langkah pembuatan e-modul pada HP android. Hal ini ditunjukkan dengan berhasilnya peserta megubah file modul dalam bentuk ektensi.doc ke bentuk ekstensi.epub.Epub (electronic publication) merupakan salah satu format digital book yang merupakan format standardisasi bentuk, diperkenalkan oleh International Digital Publishing Forum (IDPF) pada Oktober 2011. Epub menggantikan peran Open eBook sebagai format buku terbuka. Epub terdiri atas file multimedia, html5, css, xhtml, xml yang dijadikan satu file dengan ekstensi .epub.

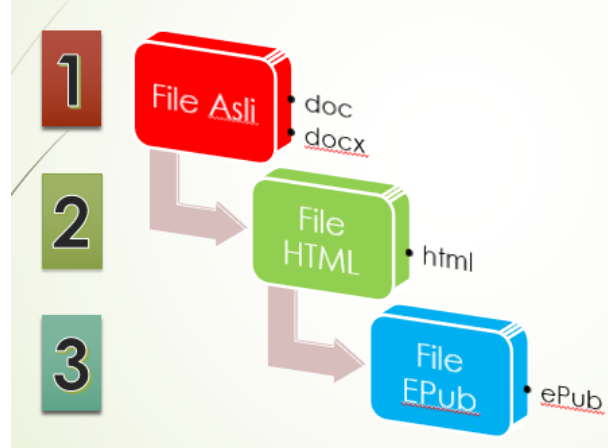

Gambar 2. Proses Konversike digital e Book

Pada langkah pertama dan kedua menggunakan software pengolahan
kata/Ms Word. Pada langkah ketiga menggunakan software Sigil.

3. Peningkatan pemahamanbagi pengurus MGMP Matematika SMK Kabupaten Malang terhadap pengelolaan organisasi. Hal ini ditunjukkan dengan hasil rumusan progran kegiatan tahunan MGMP.

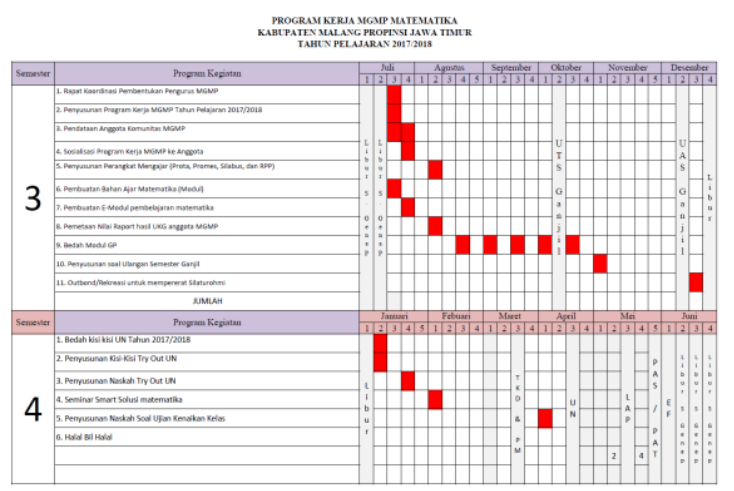

Gambar 3.Hasil rumusan program kerja tahunan.

Gambar 3 menunjukkan progam kerja MGMP Matematika SMK Kabupaten Malang pada semester gasal 2017/2018.

4. Peningkatan dalam pengelolaan kegiatan-kegiatan MGMP. Peningkatan dalam pengelolaan kegiatan ini terlihat pada pelaksanaan kegiatan yang terakhir, yaitu pada kegiatan desiminasi hasil pembuatan emodul. Panitia yang dibentuk bisa menjalankan tugasnya masingmasing. Sehingga tim pengabdian masyarakat tidak mendampinginya lagi. Hal ini berbeda dengan pelaksanaan kegiatan yang pertama, yaitu workshop pembuatan modul. Walaupun sudah dibreefing oleh tim pengabdian, tapi pada pelaksanaanya ada panitia yang belum menjalankan tugasnya. Sehingga pada saat pelaksanaan 


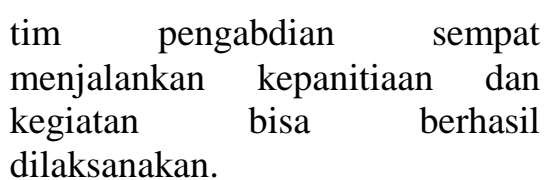

Ketrampilan pembuatan e-modul merupakan salah satu ketrampilan guru dalam penggunaan teknologi. Penggunaan teknologi ini tentunya berpengaruh terhadap peningkatan pendidikan pada umumnya. Teknologi terutama teknologi informasi dan komunikasi bias digunakan sebagai alat bantu untuk mengumpulkan, mengelola, menyimpan, menyelidiki, membuktikan dan menyebarkan informasi penting secara efektif dan efisien(Munir, 2009). Hal ini bias digunakan untuk menyebarkan materi pembelajaran. Begitu juga guru sebagai aktor utama dalam proses pendidikan dituntut harus dengan cepat memperbaharui pengetahuan, keterampilan, dan kompetensinya dalam bidang Teknologi Informasi dan Komunikasi (TIK), tak terkecuali guru produktif Sekolah Menengah Kejuruan (SMK (Fitriyadi, 2012).

Modul matematika SMK dan emodul yang dihasilkan dari kegiatan ini bermanfaat dalam meningkatkan pembelajaran matematika SMK, terutama untuksiswa yang melaksanakan prakerin.Mereka bias berinteraksi dengan sumber belajar dengan mudah sehingga pembelajaran bias berjalan. Dalam undangundang no 20 menyatakan bahwa yang dimaksud pembelajaran adalah proses interaksi peserta didik dengan pendidik dan sumber belajar pada suatu lingkungan belajar.

\section{SIMPULAN}

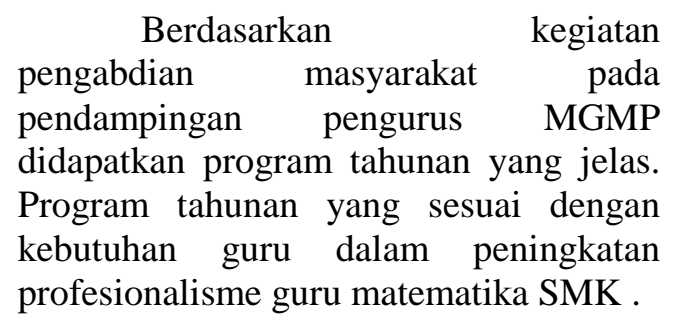

Peningkatan pemahaman dalam langkah-langkah pembuatan e-modul pada guru matematika SMK kabupaten Malang merupakan hasil kegiatan dari workshop dan pelatihan e-modul. Secara umum produk yang dihasilkan adalah program tahunan MGMP dan e-modul matematika SMK.

\section{DAFTAR PUSTAKA}

Kusufa, R. A.B., (2013). Pengaruh Kompetensi Pedagogik Dan Kesiapan Guru Terhadap Implementasi Kurikulum 2013, 186-196. ejournal.unikama.ac.id/index.php/JPI G/issue/download/260/32

Anwar, R. (2011). Pengaruh Musyawarah Guru Mata Pelajaran (MGMP) terhadap Peningkatan Profesionalisme dan Kinerja Mengajar Guru SMA Negeri Kota Tasikmalaya. Jurnal Administrasi Pendidikan, 13. Retrieved from http://ejournal.upi.edu/index.php/JAP SPs/article/view/6393

Arfandi, A. (2009). Pelaksanaan Praktek Kerja Industri Siswa Smk Program Keahlian Teknik Bangunan Di Kota Makassar. Cakrawala Pendidikan, XXVIII, (2), 119-131.

Fitriyadi, H. (2012). Ketrampilan TIK guru Produktif SMK di Kabupaten Hulu Sungai Utara dan Implementasi dalam Pembelajaran, Jurnal Pendidikan Vokasi, 2, (2), 213-233.

Husain, C. (2014). Pemanfaatan Teknologi Informasi dan Komunikasi dalam Pembelajaran di SMA Muhammadiyah Tarakan. Jurnal Kebijakan Dan Pengembangan Pendidikan, 2(2), 184-192.

Kemendikbud. (2013). Diklat Guru dalam Rangka Implementasi Kurikulum 2013. Jakarta: BSNP. 
Mahmud, I. (2013). Musyawarah Guru Mata Pelajaran (MGMP) Sejarah untuk Meningkatkan Profesionalisme Guru SMA di Kota Batu.http://karyailmiah.um.ac.id/index.php/sejarah/arti cle/view/23807

Munir. (2009). Kontribusi Teknologi Informasi dan Komunikasi (TIK) dalam Pendidikan Di Era Globalisasi
Pendidikan Indonesia.Jurnal Pendidikan Teknologi Informasi Dan Komunikasi (PTIK). 2, (2), 1-4.

Zuriah, N., Sunaryo, H., \& Yusuf, N. (2016). IbM Guru dalam Pengembangan Bahan Ajar Kreatif Inovatif Berbasis Potensi Lokal. Jurnal Dedikasi, 13, 39-49. 